\title{
Pulmonary involvement in brucellosis
}

\author{
Mehmet Uluğ MD¹, Nuray Can-Uluğ MD²
} M Uluğ, N Can-Uluğ. Pulmonary involvement in brucellosis.
Can J Infect Dis Med Microbiol 2012;23(1):e13-e15.

BACKGROUND: Brucellosis is a zoonotic disease caused by a Gramnegative bacillus of the Brucella genus with multisystem involvement, primarily affecting the reticuloendothelial system, joints, heart and kidneys. Although the disease can be spread by inhalation, pulmonary involvement is rare.

OBJECTIVE: To report a case of brucellosis with pulmonary involvement.

CASE PRESENTAION: A previously healthy 36-year-old woman was admitted with complaints of fever, weakness, night sweats, dry cough and bilateral chest pain. She hed been diagnosed with pneumonia 20 days previously and was started on a course of ampicillin for 14 days, with no response. Her chest auscultation revealed diminished breath sounds and scattered crackles and rhonchi over the inferior zone of the right hemithorax. Wright and Coombs testing resulted in titres of $1: 1280$ and 1:640, respectively. Chest radiography revealed an area of confluent lobar consolidation in the right lower lobe. Treatment was started with a six-week course of oral doxycycline $200 \mathrm{mg} /$ day and rifampicin $600 \mathrm{mg} /$ day. This treatment regimen rapidly improved the patient's condition. Follow-up after one year showed no residual effects from the infection.

CONCLUSION: Pulmonary involvement is a rare event in the course of brucellosis, but the rate could be higher than currently estimated. In endemic regions, brucellosis should be considered as a causative agent in patients with pulmonary symptoms.

\section{L'atteinte pulmonaire en cas de brucellose}

HISTORIQUE : La brucellose est une zoonose causée par un bacille Gram négatif du gène Brucella associée à une atteinte multisystémique, touchant principalement le système réticuloendothélial, les articulations, le cœur et les reins. Même si la maladie peut se propager par inhalation, l'atteinte pulmonaire est rare.

OBJECTIF : Rendre compte d'un cas de brucellose associé à une atteinte pulmonaire.

PRÉSENTATION DE CAS : Une femme de 36 ans auparavant en santé a été hospitalisée parce qu'elle se plaignait de fièvre, de faiblesse, de sueurs nocturnes, d'une toux sèche et de douleurs thoraciques bilatérales. On lui avait diagnostiqué une pneumonie 20 jours auparavant et elle avait entrepris un traitement à la pénicilline de 14 jours, auquel elle n'avait pas répondu. L'auscultation pulmonaire a révélé un murmure vésiculaire réduit dans la zone inférieure ainsi que des craquements dispersés et des râles continus dans la zone inférieure de l'hémithorax droit. Les tests de Wright et de Coombs ont donné des titrages de 1:1280 et de 1:640, respectivement. La radiographie pulmonaire a révélé une zone de condensation lobaire confluente dans le lobe inférieur droit. Le traitement a été amorcé par $200 \mathrm{mg} /$ jour de doxycycline et $600 \mathrm{mg} / \mathrm{jour}$ de rifampicine par voie orale pendant six semaines, lequel a rapidement amélioré l'état de la patiente. Le suivi au bout d'un an n'a révélé aucun effet résiduel de l'infection.

CONCLUSION : L'atteinte pulmonaire est rare dans l'évolution de la brucellose, mais le taux pourrait être plus élevé que les estimations actuelles. Dans les régions endémiques, la brucellose devrait être considérée comme un agent causal chez les patients présentant des symptômes pulmonaires.

Key Words: Brucellosis; Complication; Lung

$\mathrm{B}$ rucellosis is a worldwide re-emerging zoonosis caused by organisms belonging to the genus Brucella, which are Gram-negative, nonspore-forming, facultative intracellular bacteria (1). The incidence of the disease in Turkey is 0.59 per 100,000 persons per annum, and worldwide there are 500,000 new cases of brucellosis reported annually (2). The primary mode of transmission is through consumption of nonpasteurized milk or cheese from infected goats, sheep or cows, the consumption of contaminated meat or by direct contact with infected animals (3).

Characteristic symptoms such as undulant fever and malaise are seen in most patients. Focal manifestations are found in the joints and bones (spondylitis, sacroiliitis, arthritis), in the respiratory tract (pneumonia, pleuritis), in the cardiovascular system (endocarditis, pericarditis, vasculitis), the nervous system (radiculitis, meningoencephalomyelitis), the urogenital system (nephritis, epididymitis, orchitis) as well as in the liver, spleen and skin (1-3).

Pulmonary involvement is extremely rare in the course of brucellosis and it may only appear as a chest radiograph abnormality, or it may be part of a systemic illness (4). Most large studies of patients with brucellosis have only occasionally focused on the respiratory system, with an estimated rate of involvement in less than $1 \%$ to $5 \%$ of cases (5). Inhalation of contaminated aerosols and bacteremic spread to the lungs are the most probable routes for acquiring pulmonary brucellosis (6). A variety of pulmonary manifestations associated with brucellosis have been documented in the literature, including bronchopneumonia, lung abscess, empyema, pleural effusion, granulomas, solitary nodules, and hilar and paratracheal lymphadenopathy $(1,4)$. In the present report, a case of brucellosis with pulmonary involvement was presented along with a review of the current literature.

\section{CASE PRESENTATION}

A previously healthy, 36-year-old woman was admitted to the Department of Infectious Diseases, Midyat State Hospital, Mardin in the Southeastern Anatolia region of Turkey, in June 2007, with an approximately 25-day history of fever, weakness, night sweats, dry cough and bilateral chest pain. She had been diagnosed with pneumonia 20 days previously in the emergency department of the hospital. At that time, she was started on intravenous ampicillin $3 \mathrm{~g} /$ day for 14 days, but showed no response to this therapy. Her history indicated that she lived in an area endemic for brucellosis, a village where sheep and goats are raised, where consumption of unpasteurized milk products is common. Apart from her diagnosis of pneumonia, the patient's medical history was unremarkable, with no history of drug or food allergies.

On the day of admission, physical examination revealed that she was febrile $\left(38.2^{\circ} \mathrm{C}\right)$ and in poor general appearance. Blood pressure, pulse and respiratory rate were $100 / 70 \mathrm{mmHg}, 96$ beats/min and 24 breaths/min, respectively. Her chest auscultation revealed diminished breath sounds and scattered crackles and rhonchi over the inferior zone of the right hemithorax. Her liver was palpable $2 \mathrm{~cm}$ below the right costal margin. Other physical findings were normal.

\footnotetext{
${ }^{1}$ Department of Infectious Diseases and Clinic Microbiology; ${ }^{2}$ Department of Neurology, Özel Ümit Hospital, Turkey

Correspondence: Dr Mehmet Uluğ, Özel Ümit Hastanesi, Enfeksiyon Hastalıları ve Klinik Mikrobiyoloji Kliniği, 26140 Eskiş̧ehir, Turkey.

Telephone 905324475756, fax 902223350170, e-mail mehmetulug21@yahoo.com
} 


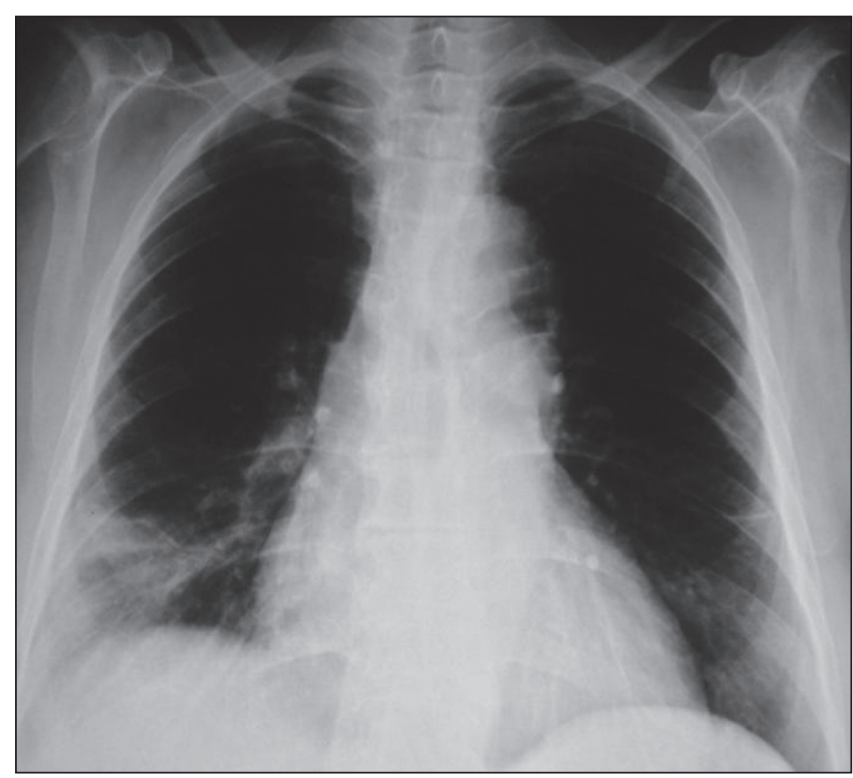

Figure 1) Lobar pneumonic consolidation in the right inferior lobe

Laboratory findings included a hemoglobin level of $131 \mathrm{~g} / \mathrm{L}$ (normal range [NR] $122 \mathrm{~g} / \mathrm{L}$ to $181 \mathrm{~g} / \mathrm{L}$ ), total leukocyte count of $10.3 \times 10^{9} / \mathrm{L}$ (80\% polymorphonuclear cells; NR $4.6 \times 10^{9} / \mathrm{L}$ to $10.2 \times 10^{9} / \mathrm{L}$ ), and platelet count of $195 \times 10^{9} / \mathrm{L}$ (NR $142 \times 10^{9} / \mathrm{L}$ to $\left.424 \times 10^{9} / \mathrm{L}\right)$. Her aspartate aminotransferase was (38 U/L, NR $10 \mathrm{U} / \mathrm{L}$ to $40 \mathrm{U} / \mathrm{L})$ and alanine aminotransferase $(47 \mathrm{U} / \mathrm{L}, \mathrm{NR} 10 \mathrm{U} / \mathrm{L}$ to $45 \mathrm{U} / \mathrm{L})$ were within normal limits. Erythrocyte sedimentation rate was $61 \mathrm{~mm} / \mathrm{h}(\mathrm{NR} 8 \mathrm{~mm} / \mathrm{h}$ to $15 \mathrm{~mm} / \mathrm{h})$ with a C-reactive protein level measuring $199.2 \mathrm{nmol} / \mathrm{L}(\mathrm{NR}<47.6 \mathrm{nmol} / \mathrm{L})$. Wright and Coombs testing showed titres of 1:1280 (cut-off value was $\geq 1: 160$ ) and 1:640, respectively. Urinalysis revealed no evidence of infection. Blood, urine and throat cultures had been performed before antibiotic therapy was started.

Chest radiography was performed at admission and showed an area of confluent lobar consolidation in the right lower lobe (Figure 1). An ultrasound of the thorax confirmed the diagnosis of lobar pneumonia and minimal reactive pleurisy.

Based on these findings, a presumptive diagnosis of brucellar pneumonia was made. Treatment was started with a six-week course of oral doxycycline $200 \mathrm{mg} /$ day and rifampicin $600 \mathrm{mg} /$ day, and her clinical condition improved rapidly after initiation of the treatment. On the fifth day of the treatment her fever started to drop, and on the seventh day she became afebrile. Other potential diagnoses and coinfections were excluded (ie, blood cultures were negative for Streptococcus pneumoniae; dermal tuberculin tests were negative; serological tests for Mycoplasma species, Chlamydia pneumoniae, Coxiella burnetii, and Legionella species were all negative, both for acute and convalescent phase specimens; and urine sample tests for Legionella pneumophila antigen were negative). Her blood cultures were also negative for Brucella species.

Her condition continued to improve and she was discharged following complete recovery after 14 days of treatment. After completion of the therapy, her agglutination test titres decreased to 1:20 and her hemogram parameters, C-reactive protein level and erythrocyte sedimentation rate were normalized. The initial pneumopleurisy appearance recovered completely on her follow-up radiographs. Follow-up after one year showed no residual effects from the infection.

\section{DISCUSSION}

Brucellosis is a systemic infectious disease. Due to its high degree of morbidity, both for animals and humans, it is a significant cause of economic loss and represents a serious public health problem in many developing countries (2). Inhalation of contaminated aerosols is a route by which Brucella can make direct contact with the respiratory system and, according to some authors, it is a route that has potential for use in biological warfare (6). Because of wide distribution of the microorganism through the bloodstream to various organs, including the lungs, bacteremic spread may be the most probable route for acquiring pulmonary brucellosis $(2,4)$.

A variety of presentations, affected organs and complications have been reported in the course of brucellosis, but pulmonary involvement is extremely rare (7). It is well known that brucellosis can initially present with atypical symptoms not unlike the symptoms of most mild upper respiratory tract infections. This presentation could be considered the respiratory mononuclear cells' reaction to the invading microbe; it is not considered to truly be respiratory involvement, by us or by most other specialists, unless it takes a prolonged and paroxysmal course (5). In the literature, the following pulmonary manifestations of brucellosis have been reported: lung abscess, empyema, pneumonia, pleural effusion, granulomas, solitary nodules, and hilar and paratracheal lymphadenopathy (4-8). Pneumonia may be the sole presentation of brucellosis (9). In the study by Lulu et al (10), pulmonary involvement was reported in four patients (1\%); three had pneumonia and one had a pleural effusion. However, the ratio of pulmonary involvement was $0.6 \%, 5 \%$ and $10 \%$ in studies by Lubani et al (7), Gür et al (2) and Hatipoğlu et al (4), respectively. Similar to cases reported in the literature, our patient presented with lobar pneumonia.

Various radiographical abnormalities are reported in brucellosis such as miliary mottling, parenchymal nodules, pneumonic consolidation, pleurisy, lung abscess, bronchiectasis, hilar or paratracheal lymphadenopathy, and pneumothorax (4-7). Clinical and radiological findings in the present case were suggestive of lobar consolidation and minimal reactive pleural effusion in the inferior zone of the right lobe.

Diagnosis depends on the presence of prolonged fever, other clinical findings suggestive of brucellosis, and serological tests with or without positive blood culture (1). In the present case, thoracentesis was not performed because the pleural effusion was minimal. According to some authors, the efficacy of blood cultures decreases significantly with the previous use of antibiotics and with subacute and chronic forms of infection $(2,6)$. Negative blood cultures in the present case may be related to the use of antibiotics before the investigation for brucellosis. Although the definitive diagnosis is established by recovering the organism in the blood, bone marrow or other tissue cultures, serodiagnostic tests continue to be important in the diagnosis of brucellosis $(6,9)$. The serum agglutination test (SAT) is the most widely used and practical test to detect antibodies against this organism. To diagnose acute cases, assays have been used to detect the presence of specific immunoglobulin (Ig) M antibodies, and these include radioimmunoassay, ELISA and the indirect immunofluorescence assay (11). The classical Rose Bengal test (RBT) is often used as a rapid screening test. The sensitivity of RBT is very high (>99\%), but the specificity can be disappointingly low (12). For confirmation of RBT, SAT, or in more sophisticated equipped laboratories, ELISA may be used (13). As guidance, agglutination at titres of 1:160 or greater are considered to be of diagnostic value as long as the patient displays signs and symptoms of the disease (14). To diagnose subacute or chronic forms of brucellosis, a Coombs test must be performed to demonstrate incomplete antibodies. Because the SAT titre may be decreased, or negative, due to blocking antibodies, it may lead to an error in diagnosis when there is no growth in blood culture (11). SAT is sometimes performed in the presence of the reducing agents 2-mercaptoethanol (2-ME) or dithiothreitol. These reducing agents destroy the agglutinating activity of IgM, leaving IgG intact (15). The 2-ME- or SAT-dithiothreitol test is used to increase the specificity of the reaction by looking at IgG only, which is important in patients with persistent infection. It may be important to note that none of the commercial ELISA systems has been properly evaluated using samples from culture confirmed patients with brucellosis and controls to define the sensitivity and specificity (14). Studies have shown that in ELISA, a strong positive signal may be obtained from 
control samples from patients with illnesses other than brucellosis (14). In brucellosis, specific IgM antibodies dominate during the acute phase of the disease (16), and specific $\operatorname{IgG}$ antibodies are present in the serum of patients at later stages of the illness as well as in the serum of relapsing patients (17). ELISA is used to discriminate between the presence of specific $\operatorname{IgM}$ and $\operatorname{IgG}$ antibodies and to approximately access the stage of illness. SAT and the 2-ME test are also used for this purpose, but are less accurate (14). The Brucella IgM/IgG flow assay, a simple and rapid diagnostic test, has a sensitivity and specificity for cultureconfirmed brucellosis of greater the $95 \%$ (12), and can be very useful (16). This test can make diagnosis much faster and it may also be used as a confirmatory test for RBT-positive samples. In the present report, the patient had a titre as high as 1:1280, which returned to $1: 20$ after completion of the therapy.

Because Brucella species are intracellular pathogens, successful treatment of brucellosis requires prolonged therapy with a

\section{REFERENCES}

1. Young EJ. Brucella species. In Mandell GL, Bennett JE, Dolin R, eds. Principles and Practice of Infectious Diseases, 6th edn. Philadelphia: Elsevier, Churchill Livingstone, 2005:2669-74

2. Gür A, Geyik MF, Dikici B, et al. Complications of brucellosis in different age groups: A study of 283 cases in Southeastern Anatolia of Turkey. Yonsei Med J 2003;44:33-44.

3. Celen MK, Ulug M, Ayaz C, Geyik MF, Hosoglu S. Brucellar epididymo-orchitis in southeastern part of Turkey: An 8 year experience. Braz J Infect Dis 2010;14:109-15.

4. Hatipoglu CA, Bilgin G, Tulek N, Kosar U. Pulmonary involvement in brucellosis. J Infect 2005;51:116-9.

5. Pappas G, Bosilkovski M, Akritidis N, Mastora M, Krteva L, Tsianos E. Brucellosis and the respiratory system.

Clin Infect Dis 2003;37:e95-9.

6. Olukman Ö. Pulmonary involvement in childhood brucellosis: A case report. Vector Borne Zoonotic Dis 2008;8:245-8.

7. Lubani MM, Lulu AR, Araj GF, Khateeb MI, Qurtom MAF, Dudin KI. Pulmonary brucellosis. Q J Med 1989;71:319-24.

8. Kerem E, Diav O, Navon P, Branski D. Pleural fluid characteristics in pulmonary brucellosis. Thorax 1994;49:89-90.

9. Abu-Ekteish F, Kakish K. Pneumonia as the sole presentation of brucellosis. Respir Med 2001;95:766-7.

10. Lulu AR, Arab GF, Khateeb MI, Mustafa MY, Yusuf AR, Fenech FF. Human brucellosis in Kuwait: A prospective study of 400 cases. Q J Med 1988;66:39-54. combination of agents that are capable of penetrating the cell. Optimal treatment of brucellosis remains based on traditional combinations of doxycycline, with addition of either rifampicin or streptomycin (18). Pulmonary brucellosis is rarely serious, and it usually responds to the standard regimens used for the treatment of uncomplicated brucellosis $(2,4)$. In the present case, a combination therapy of rifampicin and doxycycline was used successfully for six weeks.

\section{CONCLUSION}

Pulmonary involvement is a rare event in the course of brucellosis, but the rate could be higher than currently estimated. In endemic regions, brucellosis should be considered as a causative agent in patients with pulmonary symptoms. In addition, primary health care physicians should be alerted regarding the clinical and laboratory findings of Brucella complications.

11. Tanir G, Tufekci SB, Tuygun N. Presentation, complications, and treatment outcome of brucellosis in Turkish children. Pediatr Int 2009;51:114-9.

12. Mantur BG, Amarnath SK, Shinde RS. Review of clinical and laboratory features of human brucellosis. Indian J Med Microbiol 2007;25:88-202.

13. Mathai E, Singhal A, Verghese S, et al. Evaluation of an ELISA for the diagnosis of brucellosis. Indian J Med Res 1996;103:323-4.

14. Smiths HL, Kadri SM. Brucellosis in India: A deceptive infectious disease. Indian J Med Res 2005;122:375-84.

15. Al Dahouk S, Tomaso H, Nockler K, Neubauer H, Frangoulidis D. Laboratory-based diagnosis of brucellosis - a review of the literature. Part II: Serological tests for brucellosis. Clin Lab 2003;49:577-89.

16. Smits HL, Abdoel TH, Solera J, Clavijo E, Diaz R. Immunochromatographic Brucella-specific immunoglobulin $\mathrm{M}$ and $G$ lateral flow assays for rapid serodiagnosis of human brucellosis. Clin Diagn Lab Immunol 2003;10:1141-6.

17. Ariza J, Pellicer T, Pallares R, Foz A, Gudiol F. Specific antibody profile in human brucellosis. Clin Infect Dis 1992;14:131-40.

18. Ariza J, Bosilkovski M, Cascio A, et al. Perspectives for the treatment of brucellosis in the 21st century:

The Ioannina recommendations. PLoS Med 2007;4:e317. 


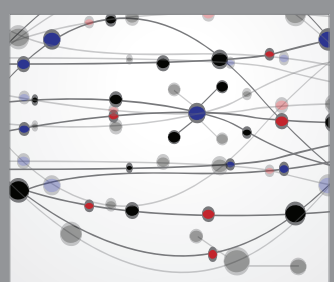

The Scientific World Journal
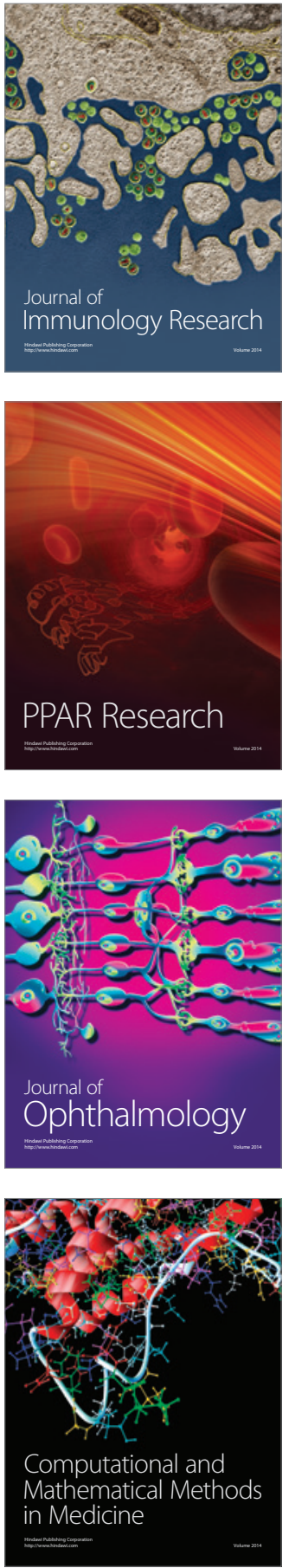

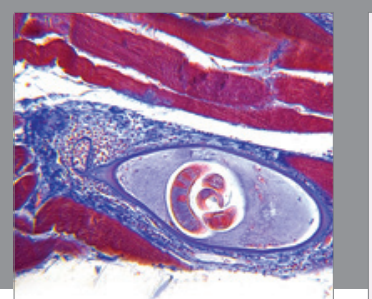

Gastroenterology Research and Practice

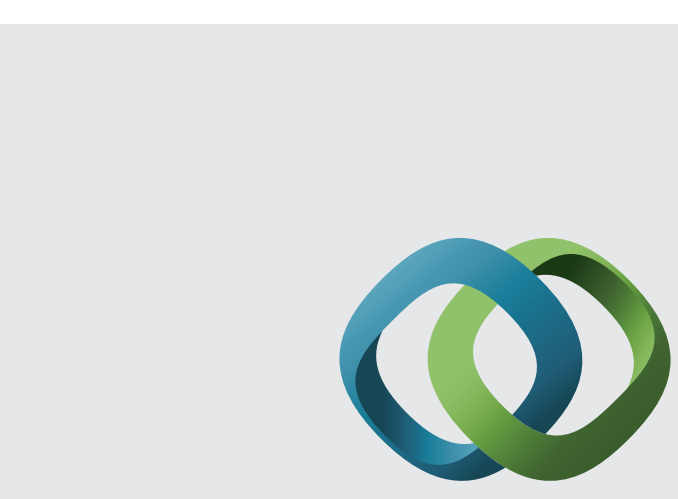

\section{Hindawi}

Submit your manuscripts at

http://www.hindawi.com
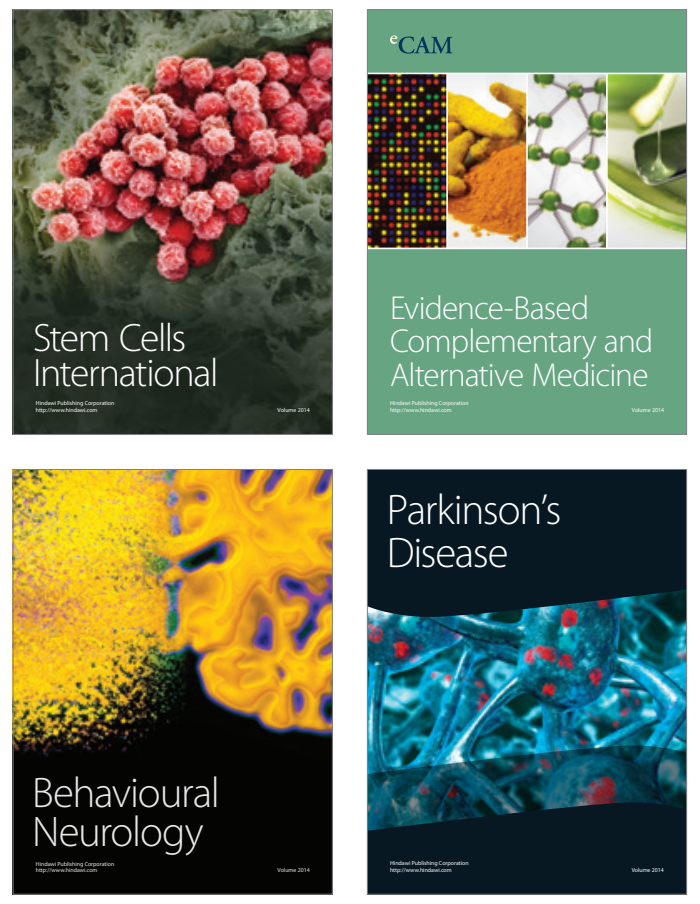
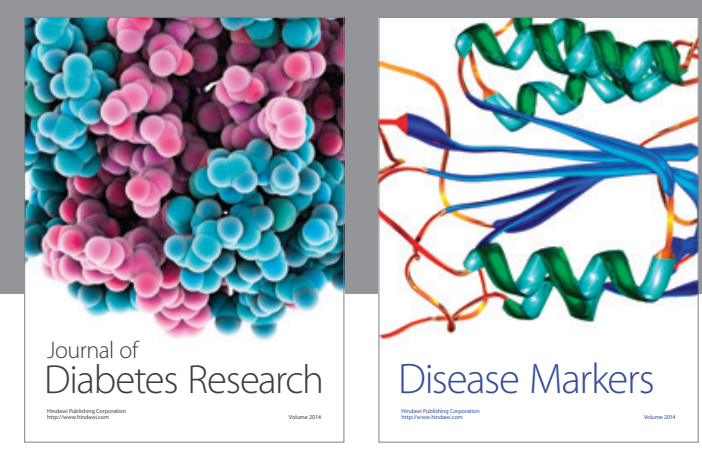

Disease Markers
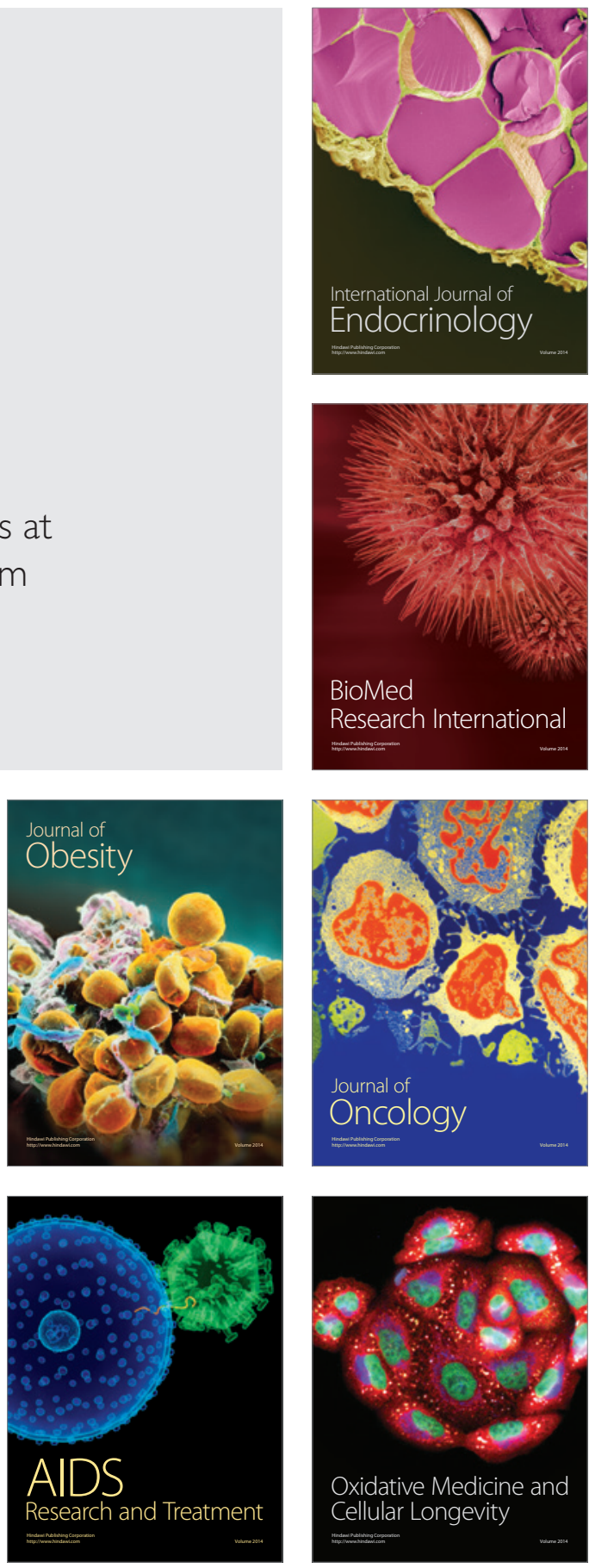